\title{
Magnetic Field Dependence of Low Temperature Specific Heat Jump in Superconducting Crystal
}

\author{
Cheol Ho $\mathrm{Kim}^{\dagger}$ \\ Department of Electronic and Optical Engineering, Honam Univiversity, Gwangju 506-714, Korea
}

(2010년 12월 6일 접수 : 2010년 12월 9일 최종수정 : 2010년 12월 10일 채택)

\begin{abstract}
Specific heat of a crystal is the sum of electronic specific heat, which is the specific heat of conduction electrons, and lattice specific heat, which is the specific heat of the lattice. Since properties such as crystal structure and Debye temperature do not change even in the superconducting state, the lattice specific heat may remain unchanged between the normal and the superconducting state. The difference of specific heat between the normal and superconducting state may be caused only by the electronic specific heat difference between the normal and superconducting states. Critical temperature, at which transition occurs, becomes lower than $T_{\mathrm{c} 0}$ under the influence of a magnetic field. It is well known that specific heat also changes abruptly at this critical temperature, but magnetic field dependence of jump of specific heat has not yet been developed theoretically. In this paper, specific heat jump of superconducting crystals at low temperature is derived as an explicit function of applied magnetic field $H$ by using the thermodynamic relations of A. C. Rose-Innes and E. H. Rhoderick. The derived specific heat jump is compared with experimental data for superconducting crystals of $\mathrm{MgCNi}_{3}, \mathrm{LiTi}_{2} \mathrm{O}_{4}$ and $\mathrm{Nd}_{0.5} \mathrm{Ca}_{0.5} \mathrm{MnO}_{3}$. Our specific heat jump function well explains the jump up or down phenomena of superconducting crystals.
\end{abstract}

Key words specific heat jump, superconductor, magnetic field, thermodynamics.

\section{1. 서 론}

결정에 열을 가하면 결정 격자와 전도 전자의 온도가 상 승된다. 따라서 결정의 비열은 격자에 의한 비열과 전도 전자에 의한 비열의 합으로 주어진다. Debye 모형에 의 하면 비열 $C$ 는 온도 $T$ 의 함수로서 $C=\gamma T+A T^{3}$ 과 같이 주 어진다. 이 식은 많은 결정의 실제 비열을 잘 묘사한다. 여기서 $\gamma T$ 가 전자 비열, $A T^{3}$ 이 격자 비열에 해당된다. 계 수 $\gamma$ 와 $A$ 는 결정의 종류에 따라 달라진다. Debye 모형의 비열 식은 양변을 $T$ 로 나누어 $C / T=\gamma+A T^{2}$ 의 형태로 나 타내기도 한다. 이 형태의 식은 실험을 통해 얻는 비열 값 을 정리할 때 편리하다. $C / T, T^{2}$ 축 상에서 절편 $\gamma$ 는 극저 온에서의 비열을 그리고 기울기 $A$ 는 비열의 변화율을 잘 보여주기 때문이다.

비열은 초전도 현상과 밀접한 관계에 있다. 결정 구조, Debye 온도 등과 같은 격자의 성질은 결정이 초전도 상

${ }^{\dagger}$ Corresponding author

E-Mail : chkim@honam.ac.kr (C. H. Kim)
태로 전이되더라도 변하지 않는다. 그러므로 격자에 의한 비열은 초전도 상태에서나 상전도 상태에서나 어느 쪽이 든 같다. 따라서 초전도 상태와 상전도 상태의 비열 값 의 차이는 전도 전자에 의한 비열 변화 만에 의한 것이 다. 임계 온도 바로 아래의 온도에서는 상전도 상태보다 초전도 상태의 비열이 더 높다. 이는 비열은 $C=T d S / d T$ 로 나타내어지기 때문에, 결정이 임계 온도를 지나 냉각 되어질 때 전도 전자의 엔트로피 감소가 상전도 상태일 때 보다 초전도 상태일 때가 더 급격하다는 것을 의미한다. 여기서 $S$ 는 엔트로피이다. 초전도체 결정이 냉각 될 때는 일반 결정이 냉각될 때 발생하는 통상적인 전도 전자의 엔 트로피 감소뿐만 아니라, 임계 온도에서 특별한 형태의 전 자 질서의 형성도 동시에 일어나게 된다. 전자 질서의 새 로운 형성은 온도가 낮아짐에 따라 증가하게 된다. 즉, 온 도 변화에 대한 엔트로피의 변화율을 높이게 됨으로서 비 열이 상승하게 되는 것이다. ${ }^{1-5)}$

초전도체 결정을 냉각하여 상전도 상태에서 초전도 상 태로 전이(이하 상전도-초전도 전이)가 일어나면 앞서 설 명한 바와 같이 전도 전자의 질서가 변하게 되어 전자 비 
열 값이 갑자기 불연속적으로 변화하게 된다. 그러므로 임 계 온도 이하의 온도에서는 $C / T=\gamma+A T^{2}$ 와 같은 비열 식 은 더 이상 적용할 수가 없게 된다. 임계 온도 $T_{c}$ 에서 상 전도-초전도 전이가 일어날 때의 비열 변화량 $\Delta C\left(T_{\mathrm{c}}\right)$ 를 $\Delta C\left(T_{\mathrm{c}}\right) \equiv C_{\mathrm{s}}\left(T_{\mathrm{c}}\right)-C_{n}\left(T_{\mathrm{c}}\right)$ 와 같이 정의하기로 한다. 여기서 첨자 $s$ 는 초전도 상태, $n$ 은 상전도 상태를 의미한다. 만 약 상전도-초전도 전이 시 비열이 점프 업 하게 되면 비 열 변화량 $\Delta C\left(T_{\mathrm{c}}\right)$ 의 부호는 양이 되고, 점프 다운 하게 되면 비열 변화량 $\Delta C\left(T_{\mathrm{c}}\right)$ 의 부호는 음이 된다.

외부로부터 자기장이 인가되지 않을 경우, 전이 시의 비 열 변화량 $\Delta C\left(T_{\mathrm{c}}\right)$ 는 Rutgers의 식으로 불리우는 $\Delta C\left(T_{\mathrm{c}}\right)=$ $\mu_{0} T_{c 0}\left(\left(d H_{c T} d d T\right)^{2}\right)_{T=T_{c}}$ 으로 주어진다. 여기서 $\mu_{0}$ 는 투자 상 수, $T_{c 0}$ 는 인가 자기장이 없는 경우의 임계 온도 그리고 $H_{c T}$ 는 온도 $T$ 에서의 임계 자기장을 의미한다. Rutgers 식 의 값은 양의 부호이다. 이는 외부 자기장이 없는 상태 에서 상전도 상태의 결정을 냉각시켜 가면 임계 온도에 서 초전도 상태로 전이할 때 비열이 점프 업 된다는 사 실을 잘 설명하고 있다. ${ }^{5)}$

자기장이 인가되면 전이가 일어나는 임계 온도는 $T_{c 0}$ 보 다 낮아지게 되며, 이 경우에도 해당 임계 온도에서 비 열 점프가 일어난다는 사실은 실험과 이론을 통해 잘 알 려져 있다. ${ }^{6-17)}$ 자기장 인가 시의 비열 점프에 관한 이론 적 고찰은 실험에 비해 상대적으로 활발하지 않다. 이런 가운데서도 예를 들어, A. Kallio 등과 C. P. Sun 등은 전자 비열 계수 $\gamma$ 를 자기장의 함수로 계산하여 이로부터 자기장 인가 시의 $\mathrm{YBa}_{2} \mathrm{Cu}_{3} \mathrm{O}_{6.97}$ 결정과 $\mathrm{LiTi}_{2} \mathrm{O}_{4}$ 결정의 비열 점프 현상을 각각 설명하였다. ${ }^{13,14)}$ 그리고 A. C. Rose-Innes 등은 초전도 상태와 상전도 상태의 비열 차 에 관한 열역학 관계식을 다음과 같이 제시하였다. ${ }^{15)}$

$$
C_{s}(T, H)-C_{n}(T, H)=\mu_{0} T\left(\frac{d}{d T} H_{c T}\right)^{2}+\mu_{0} H_{c T} T \frac{d^{2}}{d T^{2}} H_{c T}
$$

이 식은 자기장 $H$ 가 인가되어 임계 온도가 $T_{c 0}$ 로부터 $T$ 로 낮아진 경우의 비열 차를 나타낸다. 이 식은 측정된 임계 자기장 곡선과 열역학적 특성 간의 관계를 잘 나 타내고 있다. 즉, 임계 자기장의 곡선의 기울기를 측정하 여 특정 임계 온도에서의 비열 불연속 정도를 유도해 낼 수 있다. 임계 자기장 곡선은 자기장의 존재와는 무관한 그 결정의 특성이다. 이 식은 자기장을 외형적으로 포함 하고 있지 않으므로 이 식으로부터 직접적으로 자기장과 비열 점프 폭 간의 관계를 추정할 수는 없다.

본 논문의 목적은 다음과 같다. 첫째는, 초전도체 결정 에 자기장 $H$ 가 인가되고 있는 경우, 해당 임계 온도에서 의 비열 점프(업 혹은 다운)의 폭을 인가 자기장 $H$ 의 함 수로 유도한다. 식의 유도는 A. C. Rose-Innes 등에 의한 열역학 관계식, 식 (1)을 출발점으로 한다. 둘째는, 여기
서 유도한 식의 정당성을 실험치와의 비교를 통해 평가 하는 것이다.

\section{2. 계산 방법}

식 (1)의 임계 자기장 $H_{c T}$ 는 온도 $T$ 의 함수로서 결정 의 종류에 따라 그 값이 달라진다. 그러나 $H_{C T}$ 에 관한 다 음 관계식은 많은 초전도체에 두루 적용할 수 있는 유 용한 근사식으로 알려져 있다. ${ }^{1)}$

$$
H_{c T}=H_{c 0}\left(1-\left(\frac{T}{T_{c 0}}\right)^{2}\right)
$$

여기서 $H_{c 0}$ 는 절대 영도인 경우의 임계자기장이다. 식 (1)의 도함수 부분을 식 (2)를 이용해 계산하여 정리하면, 식 (1)은 다음 식으로 된다.

$$
C_{s}(T, H)-C_{n}(T, H)=\frac{4 \mu_{0} H_{c 0}^{2} T^{3}}{T_{c 0}^{4}}-\frac{2 \mu_{0} H_{c 0} H_{c T} T}{T_{c 0}^{2}}
$$

그러면 자기장 $H$ 가 인가 될 때의 임계 자기장 $T_{c H}$ 에 서의 비열 점프 폭 $\Delta C\left(T_{c H}, H\right)$ 는

$$
\begin{aligned}
& \Delta C\left(T_{c H}, H\right)=\left(C_{s}(T, H)-C_{n}(T, H)\right)_{\mathrm{T}=T_{c H}} \\
& =\frac{4 \mu_{0} H_{c 0}^{2} T_{\mathrm{cH}}^{3}}{T_{c 0}^{4}}-\frac{2 \mu_{0} H_{c 0} H T_{c H}}{T_{c 0}^{2}}
\end{aligned}
$$

가 된다. 식 (2)를 변환하면 $T_{c H}$ 를 다음과 같이 나타낼 수 있다.

$$
T_{c H}=T_{c 0}\left(1-\frac{H}{H_{c 0}}\right)^{1 / 2}
$$

식 (4), (5)의 유도에는 $\left(H_{c T}\right)_{T=T_{c H}}=H$ 가 적용되었다. 식 (4)에 식 (5)를 대입하면

$$
\Delta C\left(T_{c H}, H\right)=\frac{4 \mu_{0} H_{c 0}^{2}}{T_{c 0}}\left(1-\frac{H}{H_{c 0}}\right)^{1 / 2}\left(1-\frac{3 H}{2 H_{c 0}}\right)
$$

으로 된다. 식 (6)은 자기장 $H$ 가 인가 시 해당 임계 온 도 $T_{c H}$ 에서의 비열 점프의 폭을 나타낸 식으로 인가 자 기장 $H$ 를 외형적으로 포함하고 있다. 식 (6)은 결정 종 류에 따라 달라지는 $T_{c 0}$ 와 $H_{c 0}$ 만 알면, 해당 결정의 인가 자기장 $H$ 에 따른 비열 점프 폭을 바로 구할 수 있는 식 임을 알 수 있다. 식(6)은 $T_{c H}$ 를 외형적으로는 포함하고 있 지 않으며, $0 \leq H \leq H_{c 0}$ 의 자기장 범위에서 유효한 식이다.

\section{3. 결과 및 고찰}

Fig. 1은 식 (6)을 그림으로 나타낸 것이다. 가로축과 세 


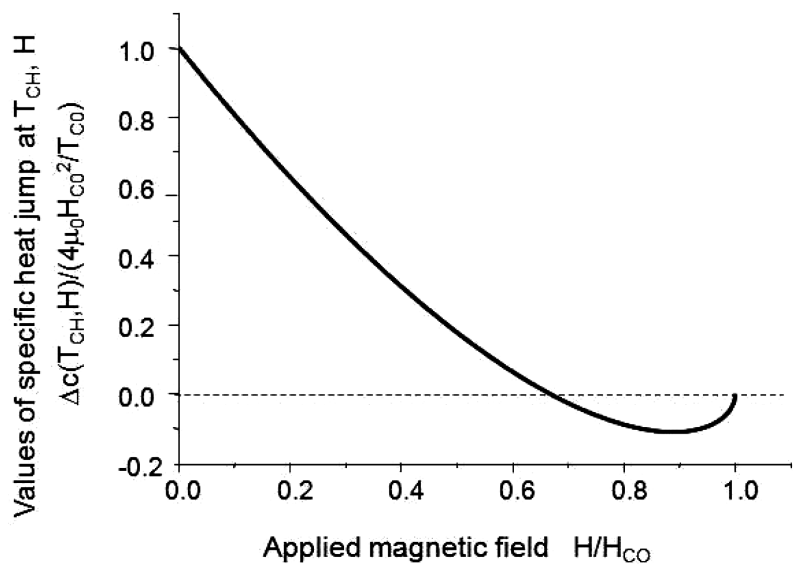

Fig. 1. Plot of values of specific heat jump at applied magnetic field $H$ and corresponding critical temperature $T_{c H}$. Both horizontal and vertical axes are reduced to dimensionless.

로축은 모두 적정 물리량으로 나누어져 무차원으로 환산 되어 있다. Fig. 1 의 가로축 절편은 $H / H_{c 0}=2 / 3,1$ 이며 $H /$ $H_{c 0}=8 / 9$ 에서 곡선은 최소치를 나타내고 있다. Fig. 1 의 곡 선을 분석해 보면 다음의 (a) (d)와 같은 특성을 내포하 고 있음을 알 수 있다. (a)인가 자기장 $H$ 가 $0<H<2 H_{c 0}$ l 3 인 영역에서는 비열 점프의 폭 $\Delta C$ 의 부호가 양이므로 냉각 과정에서 상전도-초전도 전이 시 비열은 점프 업 하게된다. (b)그리고 이 자기장 영역에서는 자기장이 세 어질수록 비열 점프 폭 $\Delta C$ 가 줄어든다. (c)인가 자기장 이 세어져 $H=2 H_{c 0} / 3$ 이상의 영역에서는 비열 점프의 폭 $\Delta C$ 의 부호가 음이므로 상전도-초전도 전이 시 비열은 점 프 다운하게 된다. (d)또한 $H=2 H_{c 0} / 3$ 이상의 자기장 영 역 중에서도 $H=8 H_{c 0} / 9$ 까지는 자기장이 세어질수록 비 열 점프 다운의 폭이 커져가지만 $H=8 H_{c 0} / 9$ 을 넘어서게

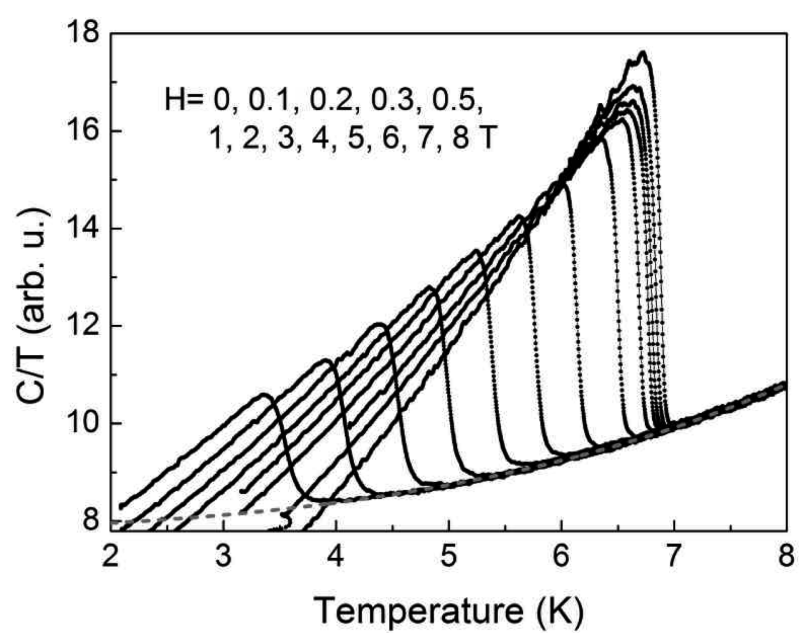

Fig. 2. Specific heat anomaly measured in magnetic fields $0 \mathrm{~T}, 0.1 \mathrm{~T}$, 0.2 T, 0.3 T, 0.5 T, 1 T, 2 T, 3 T, 4 T, 5, 6, 7 and in 8 Tesla. Dashed line corresponds to the normal state specific heat as calculated from the formula $C / T=\gamma+A T^{2}+B T^{4}$.
되면 자기장이 세어질수록 비열 점프 다운의 폭은 다시 작아져 간다. 특성 (c), (d)는 냉각 과정의 상전도-초전도 전이 시 비열이 점프 다운되는 현상을 예측한 것으로 주 목할 만한 것이다.

\section{4. 실험과의 비교}

2009년 25th International Conference on Low Temperature Physics (LT25)에서 J. Kacmarcik 등은 초전도체 인 $\mathrm{MgCNi}_{3}$ 단결정의 비열을 인가 자기장에 따라 측정 한 실험 결과를 보고하였다. ${ }^{16)}$ 이들은 자기장 $H$ 를 $0 \mathrm{~T}$ 에 서 $8 \mathrm{~T}$ 까지 올려 가면서 저온 영역에서의 비열을 측정하 여 그 결과를 Fig. 2와 같이 그림으로 정리하였다. Fig. 2 는 참고 문헌 16 의 Fig. 3 을 전재한 것이다.

Fig. 2에는 $0 \mathrm{~T} \leq H \leq 8 \mathrm{~T}$ 영역의 13 개 $H$ 값에 대응하는 13 개의 비열 곡선이 그려져 있다. 제일 높은 온도에서 피 크 값을 갖는 곡선이 $H=0$ T인 경우의 비열 곡선이며 피 크 온도가 낮아지는 쪽으로 순차적으로 자기장 $H$ 가 높 아지는 비열 곡선에 해당된다. 전이가 일어나는 중간 지 점의 온도가 임계 온도에 해당된다. 그러므로 Fig. 2 는 자 기장이 세어질수록, 초전도-상전도 전이가 일어나는, 임계 온도가 낮아지는 현상을 잘 나타내고 있다. J. Kacmarcik 등은 참고 문헌 16 에서, 절대 온도가 영일 때의 $\mathrm{MgCNi}_{3}$ 단결정의 상부 임계 자기장 $H_{c 2}(0)$ 를 $12 \mathrm{~T}$ 정도로 평가 하였다. $\mathrm{MgCNi}_{3}$ 와 같은 제 2종 초전도체의 $H_{c 2}(0)$ 는 식 (6)의 $H_{c 0}$ 에 해당되므로 $2 H_{c 0} / 3=8 \mathrm{~T}$ 가 된다.

Fig. 2 에서 $0<H<2 H_{c 0} / 3$ 영역 즉, $0 \mathrm{~T}<H<8 \mathrm{~T}$ 영역에 속하는 비열 곡선으로는 주어진 13 개 곡선 모두가 해당 되며, 이들 13 개 비열 곡선은 모두 냉각되는 온도 방향으

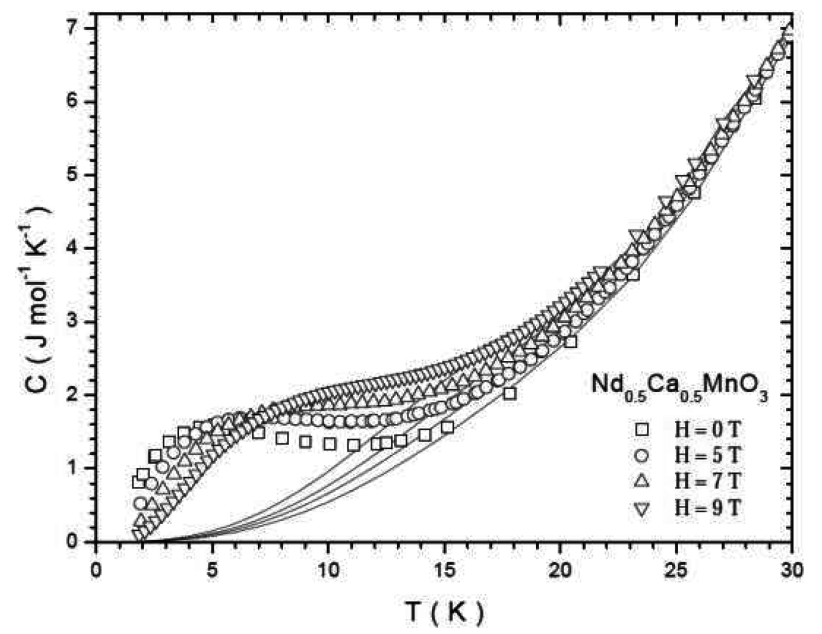

Fig. 3. Specific heat measurements between 2 and $30 \mathrm{~K}$ of $\mathrm{Nd}_{0.5^{-}}$ $\mathrm{Ca}_{0.5} \mathrm{MnO}_{3}$. Measurements were made in the presence of applied magnetic fields of $0 \mathrm{~T}$ (squares), $5 \mathrm{~T}$ (circles), $7 \mathrm{~T}$ (up triangles) and $9 \mathrm{~T}$ (down triangles). 
로의 전이 즉, 상전도-초전도 전이 시에 비열 값이 갑자 기 높아지는 비열 점프 업을 나타내고 있다. 이 점은 이 론 특성 (a)를 잘 반영하고 있다. 그리고 Fig. 2 의 $0 \mathrm{~T}<$ $H<8 \mathrm{~T}$ 영역에 속하는 13 개 곡선들은 피크 온도가 낮아 지는 순서 즉, 자기장이 높아지는 순서대로 곡선의 점프 폭이 거의 선형적으로 줄어들고 있음을 생생하게 잘 보 여주고 있다. 이것은 이론 특성 (b)를 만족시키고 있다. 이상에서 본 바와 같이 식 (6) 혹은 Fig. 1이 내포하고 있는 이론 특성 (a), (b), (c), (d) 중, 특성 (a)와 (b)는 J. Kacmarcik 등이 보고한 실험 사실과 잘 일치하고 있다. 다른 실험 예를 들어 보면, C. P. Sun 등은 $H_{c 0}$ 가 $12 \mathrm{~T}$ 정도로 평가되는 $\mathrm{LiTi}_{2} \mathrm{O}_{4}$ 결정의 저온 영역에서의 비열을 $0 \mathrm{~T}$ 에서 $8 \mathrm{~T}$ 사이의 여러 자기장의 조건하에서 측정한 실 험 결과를 보고하였다. ${ }^{4)}$ 이 실험의 결과들도 이론 특성 (a)와 (b)를 잘 재현하고 있음을 확인할 수 있었다. Fig. 2 를 보면 비열 곡선의 피크 경사가 온도가 낮을수록 더 완만해진다. 그것은 $\mathrm{MgCNi}_{3}$ 결정이 제 2 종 초전도체의 특 성중의 하나인 혼합 상태를 갖기 때문인 것으로 추정된 다. 결정의 온도가 낮을수록 혼합 상태를 유지하는 자기 장 범위는 커진다.

이론 특성 (c), (d)를 평가하기 위해서는 $H=2 H_{c 0} / 3$ 이 상 즉, $H=8 \mathrm{~T}$ 이상이 인가되는 경우의 비열 곡선이 필 요하다. 그러므로 $8 \mathrm{~T}$ 이하에서만 실험한 J. Kacmarcik 등 과 C. P. Sun 등의 보고로는 특성 (c), (d)의 평가는 더 이상 불가하다.

또 다른 실험으로서, J. Lopez 등은 $\mathrm{Nd}_{0.5} \mathrm{Ca}_{0.5} \mathrm{MnO}_{3}$ 결 정에 대해 인가 자기장 $0 \mathrm{~T}, 5 \mathrm{~T}, 7 \mathrm{~T}, 9 \mathrm{~T}$ 의 각 조건하에 서 온도 $2 \mathrm{~K}$ 와 $30 \mathrm{~K}$ 사이의 비열을 측정하였다. ${ }^{17)}$

Fig. 3은 J. Lopez 등의 실험 결과를 그림으로 나타낸 것으로 참고 문헌 17 의 Fig. $3(\mathrm{~b})$ 의 일부를 전재한 것이 다. Fig. 3 을 보면 $0 \mathrm{~T}, 5 \mathrm{~T}$ 비열 곡선의 경우는 냉각 온 도 방향으로 완만하나마 변곡점을 지나면서 약간 비열이 상승하는 부분이 보인다. 변곡점의 오른쪽에 있는 극소점 과 왼쪽에 있는 극대점의 높이가 다름을 확인할 수 있으 며, 그 차이가 비열 점프 업 값에 해당된다. 이로부터 이 론 특성 (a)가 만족됨을 알 수 있다. 곡선의 극대점과 극 소점의 높이 차이는 사각형으로 표시된 $0 \mathrm{~T}$ 곡선보다 원 표시의 $5 \mathrm{~T}$ 곡선 쪽이 약간 더 작음을 읽을 수 있다. 이 것은 이론 특성 (b)에 관한 것이다. $7 \mathrm{~T}, 9 \mathrm{~T}$ 의 경우는 냉 각 온도 방향으로 비열 상승이 보이지 않으며 일정 온 도에서 변곡점을 그리면서 비열이 하강하는 부분이 나타 나고 있다. 냉각 온도 방향으로 첫 번째 변곡점과 세 번 째 변곡점 사이가 전이가 일어나는 즉, 비열 점프 다운이 일어나는 구간으로 볼 수 있으며 그 높이 차이가 비열 점 프 다운의 폭에 해당된다. 이 내용은 이론 특성 (c)의 만 족을 의미한다. 역삼각형으로 표시된 $9 \mathrm{~T}$ 곡선은 3 개의 변
곡점이 그림 상에 잘 나타나 있어 비열 다운 폭을 대략적 으로 읽어 볼 수 있으나, 삼각형으로 표시된 $7 \mathrm{~T}$ 곡선은 세 번째 변곡점까지 그려져 있지 않다. $7 \mathrm{~T}$ 곡선의 세 번째 변 곡점은 $2 \mathrm{~K}$ 이하 온도에서 존재할 것으로 예상된다.

$\mathrm{Nd}_{0.5} \mathrm{Ca}_{0.5} \mathrm{MnO}_{3}$ 결정의 경우, 전이 시의 비열 곡선의 상 승 혹은 하강의 경사가 대단히 완만하다. 그것은 앞서 언 급한 $\mathrm{MgCNi}_{3}$ 결정의 경우와 같이, $\mathrm{Nd}_{0.5} \mathrm{Ca}_{0.5} \mathrm{MnO}_{3}$ 결정 이 $250 \mathrm{~K}$ 정도의 대단히 높은 임계 온도를 갖는 제 2 종 초전도체이기 때문인 것으로 추정된다. 제2종 초전도체는 온도와 자기장에 대해 안정된 초전도성을 갖기 때문에 제 1 종 초전도체와 같이 전이가 일시에 일어나지 않고 초전 도 상태와 상전도 상태를 공유하면서 전이가 완만히 진 행되는 특성을 갖고 있다.

이상에서 J. Lopez 등의 실험 결과인 Fig. 3 의 분석을 통해 $0 \mathrm{~T}, 5 \mathrm{~T}$ 자기장에 대해 이론 특성 (a), (b)가 잘 적 용됨을 보았다. $7 \mathrm{~T}, 9 \mathrm{~T}$ 자기장에 대해서는 우선 비열 점 프 다운에 관한 이론 특성 (c)는 잘 적용됨을 확인할 수 있었다. 그러나 $7 \mathrm{~T}, 9 \mathrm{~T}$ 자기장에 대해 이론 특성 (d)를 평가하기 위해서는 $2 \mathrm{~K}$ 이하의 온도에서도 측정한 비열곡 선을 필요로 한다.

J. Lopez 등은 $\mathrm{Nd}_{0.5} \mathrm{Ca}_{0.5} \mathrm{MnO}_{3}$ 결정의 $H_{c 0}$ 값에 대해서 는 따로 제시하지 않았다. 그러므로 이론적으로 비열 점 프 다운이 일어나는 최소 자기장 값 $2 H_{c 0} / 3$ 가 어느 정 도인지 평가할 수는 없다. 하지만 앞의 고찰에서 본 바 와 같이 비열 다운이 시작되는 자기장이 $5 \mathrm{~T}$ 와 $9 \mathrm{~T}$ 사이 였으므로 $2 H_{c 0} / 3$ 값도 그에 준한다고 볼 수 있다. 따라 서 $\mathrm{Nd}_{0.5} \mathrm{Ca}_{0.5} \mathrm{MnO}_{3}$ 결정의 $H_{c 0}$ 는 $7.5 \mathrm{~T} \sim 13.5 \mathrm{~T}$ 정도로 추 정된다.

\section{5. 결 론}

이상에서 비열 점프에 관한 이론식, 식 (6)과 실험으로 관측한 $\mathrm{MgCNi}_{3}, \mathrm{LiTi}_{2} \mathrm{O}_{4}, \mathrm{Nd}_{0.5} \mathrm{Ca}_{0.5} \mathrm{MnO}_{3}$ 결정의 비열 곡 선을 비교 분석하였다. 식 (6)은, A. C. Rose-Innes의 열 역학 관계식, $H_{c T}$ 에 대한 근사식, 근사식의 역변환을 통 한 $H$ 의 표면화 등을 통해 유도된 비교적 간단한 형태의 식임에도 불구하고, 각 결정에 대해 확보된(측정된) 실험 결과를 잘 설명하고 있다. 특히 일정 세기 이상의 자기 장이 인가되면 전이 시에 비열이 점프 다운된다는 주목 할 만한 이론적 예측을 실험 데이터를 통해 확인할 수 있었던 점은 고무적이다. 금후 다수의 초전도체 결정에서 $2 H_{c 0} / 3$ 이상의 자기장에 대해 측정된 비열 데이터가 확 보되면, 식 (6)의 특성 (d), 즉 비열 점프 다운의 폭과 관 련한 이론적 예측에 대해서도 상세히 평가할 수 있을 것 이다.

본 논문에서는 “자기장이 세어질수록 비열 점프 폭이 커 
진다 작아진다" 등 식 (6)의 정성적인 경향을 주로 평가 하였다. 식 (6)은 정량적인 식으로서 결정의 $H_{c 0}$ 와 $T_{c 0}$ 가 주어지면 $H$ 값에 대한 비열 점프 폭을 정확히 수치로서 주 는 식이다. 식 (6)과 실험과의 정량적인 비교, 평가에 관 한 연구는 추후 보고할 예정이다.

\section{참 고 문 헌}

1. S. Kishino, Physics of Superconductor Electronics, 1st ed., p.1, Maruzen, Tokyo (1993) (in Japanese).

2. M. Tinkham, Introduction to Superconductivity, 3rd ed., p.18, Sangyotosho, Tokyo (1975) (in Japanese).

3. T. Sakudo, Solid State Physics : Magnetism and Superconductivity, 1st ed., p.84, Shokabo, Tokyo (1993) (in Japanese).

4. N. Michoshiba and K.Suzuki, Introduction to Physics of Superconductivity, 1st ed., p.1, Baifukan, Tokyo (1995) (in Japanese).

5. M. Yamamura, Superconductor Engineering, 5th ed., p.1, Denkigakkai, Tokyo (1994) (in Japanese).

6. H. Hiraka and Y. Endoh, J. Phys. Soc. Jpn., 68, 36 (1999).

7. J. H. Choi, H. Doh, E. M. Choi, H. J. Kim, S. I. Lee, T. Yamamoto, T. Kawae and K. Takeda, J. Phys. Soc. Jpn., 70, 3037 (2001).
8. K. Machida and M. Ichioka, Phys. Rev. B, 77, 184515 (2008).

9. J. Baak, H. B. Brom, M. J. V. Menken and A. A. Menovsky, Phys. C Supercond., 162-164, 500 (1989).

10. I. S. Eo and C. H. Kim, J. Kor. Cryst. Growth \& Cryst. Tech., 14, 17 (2004).

11. K. M. Khanna, M. S. Karap Kirui, T. W. Sakwa, P. K. Torongey, K. Y. Ayodo and S. Rotich, Indian J. Pure Appl. Phys., 45, 991 (2007).

12. C. L. Huang, J. Y. Lin. C. P. Sun, T. K. Lee, J. D. Kim, E. M. Choi, S. I. Lee and H. D. Yang, Phy. Rev. B, 73, 012502 (2006).

13. A. Kallio, V. Braysy and J. Hissa, Phys. C Supercond., 364-365, 43 (2001).

14. C. P. Sun, J. Y. Lin, S. Mollah, P. L. Ho, H. D. Yang, F. C. Hsu, Y. C. Liao, and M. K. Wu, Phys. Rev. B, 70, 054519 (2004).

15. A. C. Rose-Innes and E. H. Rhoderick, Introduction to Superconductivity, 2nd ed., p.38, Pergamon Press, New York, (1978) (in Japanese).

16. J. Kacmarcik, Z. Pribulova. C. Marcenat, P. Samuely, T. Klein, A. Demuer and S. I. Lee, J. Phys. Conf., 150, 052087 (2009).

17. J. Lopez, O. F. de Lima, P. N. Lisboa-Filho and F. M. Araujo-Moreira, Phys. Rev. B, 66, 214402 (2002). 